\title{
THE EFFECT OF MATERNAL OBESITY ON SONOGRAPHIC FETAL WEIGHT ESTIMATION
}

By

\author{
Ahmed El-Ghandor, Asem Mousa Anwar and El-Sayed El-Desouky \\ Department of Obstetrics and Gynecology, Faculty of Medicine, Al-Azhar University \\ E-mail: ahmedelghandor.ae@gmail.com
}

\begin{abstract}
Background: Obesity is one of the most serious public health challenges of the $21^{\text {st }}$ century; maternal obesity represents a challenge in the sonographic (US) assessment of fetal weight, and is a recognized risk factor for adverse pregnancy outcome.
\end{abstract}

Objective: To detect the possible effect of maternal obesity on the accuracy of sonographically estimated fetal weight in the third-trimester maximum seven days before labor and to compare the accuracy of the estimation between normal weight, overweight, and class I, class II and class III obese groups.

Patient and Methods: This was a prospective study of 150 singleton pregnancies with sonographic fetal weight estimation prior to scheduled delivery. Women were classified according to current body mass index (BMI) into five categories: normal (BMI 18.5-24.9 kg/m², $\mathrm{n}=30$ ), overweight (BMI $25.0-29.9 \mathrm{~kg} / \mathrm{m}^{2}, \mathrm{n}=$ 30), obese class I (BMI 30.0-34.9kg/m², $\mathrm{n}=30$ ), obese class II (BMI, $35.0-39.9 \mathrm{~kg} / \mathrm{m}^{2}, \mathrm{n}=30$ ) and obese class III (BMI $\geq 40.0 \mathrm{~kg} / \mathrm{m}^{2}, \mathrm{n}=30$ ). The estimated fetal weight was compared with the actual birth weight, and the difference between them was recorded as the error.

Results: There were statistically significant differences between US estimated fetal weight (EFW) and birth weight $(\mathrm{g})$ versus body mass index in obesity class II and III.

Conclusions: Maternal obesity decreased the accuracy of sonographic fetal weight estimation. Clinicians should be aware of the limitations of sonographic fetal weight estimation, especially in obese patients.

Keywords: Body mass index, fetal weight, obesity, ultrasonography.

\section{INTRODUCTION}

Obesity is one of the most serious public health challenges of the $21 \mathrm{st}$ century. Obesity has reached epidemic proportions worldwide (Tsigos et al., 2018).

American College of Obstetricians and Gynecologists committee opinion, published in 2013, estimated that at least one- third of pregnant women are obese, and $8 \%$ are extremely obese (ACOG, 2016).
The clinical significance of obesity in pregnancy is based on the associated obstetric complications. In addition to obstetric complications caused by maternal obesity, obesity may also impair the visualization of the fetal anatomy and degrade image quality, making it difficult or impossible to obtain adequate images for clinical interpretation. Obese patients with predominant subcutaneous fat will have lower quality images than non-obese patients with minimal subcutaneous fat. Ultrasound imaging of obese patients remains challenging due to the adverse 
effects of adipose tissue on the propagation of sound waves (Hendler et al., 2016 and Hendler et al., 2019).

The prediction of EFW before delivery during the third trimester plays a pivotal role in obstetric practice, with a major impact on antenatal management. Many important clinical decisions depend upon a precise and accurate assessment of sonographic EFW. For example, overestimation of fetal weight before delivery can lead to unnecessary obstetric interventions.

Conversely, underestimation of fetal weight can cause delays in essential obstetric interventions (Aksoy et al., 2015).

This study aimed to detect the possible effect of maternal obesity on the accuracy of ultrasound fetal weight estimation during the third trimester seven days before labor.

\section{PATIENTS AND METHODS}

A prospective, comparative study was conducted at Sayed Galal University Hospital. The study population was drawn from consecutive patients who underwent sonographic fetal weight estimation within seven days of delivery and who fulfilled all of the following inclusion criteria:

- Singleton pregnancy.

- Cephalic presentation.

- Pregnant between 37-42 weeks.

- Proper dating L.M.P or $1^{\text {st }}$ trimester US.

- Intact membranes.

\section{Exclusion criteria:}

- Oligohydramnios or anhydramnios.
- Any medical problems (i.e. diabetic, hypertensive, heart disease).

- Placental abnormalities (i.e. placenta previa, ablatio placenta and placental attachment abnormalities).

- Congenital fetal anomalies, hydrops, intrauterine fetal death,

- Utrine fibroids.

- Obstetric emergencies, such as antepartum hemorrhage, eclampsia and acute fetal distress.

One hundred fifty singleton pregnant women who fulfilled the inclusion criteria were included in the study. All pregnant participants were between 37 and 42 weeks of gestation with a singleton cephalic presentation, and none of the participants had any medical or obstetrical problems.

After providing informed consent, each participant completed an enrolment questionnaire that assessed medical information:

- Maternal age.

- Maternal weight.

- Maternal Height.

- Parity.

Gestational age (Gestational age was calculated based on the last menstrual period and was confirmed in all cases using crown-rump length measured during the first trimester).

Body mass index (BMI) was calculated as the weight in kilograms at the current admission visit divided by the height in meters squared.

The women were classified into five BMI categories based on their current 
BMI, according to the World Health Organization and National Institutes of Health guidelines: normal weight, BMI $18.5-24.9 \mathrm{~kg} / \mathrm{m}^{2}(\mathrm{n}=30)$; overweight, BMI $25.0-29.9 \mathrm{~kg} / \mathrm{m}^{2} \mathrm{n}=30$; obese class I, BMI 30.0-34.9 kg/m ${ }^{2} \mathrm{n}=30$; obese class II, BMI $35.0-39.934 .9 \mathrm{~kg} / \mathrm{m}^{2} \mathrm{n}=30$; obese class II, BMI $35.0-39.9 \mathrm{~kg} / \mathrm{m}^{2} \mathrm{n}=30$; and obese class III, BMI $\geq 40.0 \mathrm{~kg} / \mathrm{m}^{2} \mathrm{n}=30$.

Body mass index was used as a measure of relative maternal size because it correlates with decrease of adiposity in pregnant population and allows comparison of relative maternal size in a large population of women with varying heights.

On presentation to the labor and delivery unit, ultrasound scans were performed trans abdominally using MINDRAY DC-3 Ultrasound Machine, using convex abdominal probe with Center Frequency: 3.5 MHz.

The three measurements of each fetal parameters biparietal diameter (BPD), head circumference (HC), abdominal circumference (AC) and femur length (FL) were performed in frozen images of subsequent scans, and the means of their values were used for further analysis. The fetal BPD was measured in the standard projection of the fetal head (the maximum diameter of transverse section of the fetal skull at the parietal eminences with: a short midline, the cavum septum pellucidum and the thalami) from the outer edge of the proximal parietal bone to the inner edge of the distal parietal bone. $\mathrm{HC}$ was measured in the same plane as BPD, with an elipse measurement tool from frontal to the occipital part of the outer contour of the skull bone. AC was measured in the standard cross-sectional plane at the level of the stomach and umbilical vein/ ductus venosus complex by placing an elipse around the outer border of the abdomen. FL measured from the proximal end of the major trochanter to the distal metaphysis.

The fetal biometrics and EFW were calculated using a formula based on the descriptions provided by Hadlock et al., 2016. EFW was calculated according to the Hadlock formula: $\log 10$ weight $=1.335$ - $0.0034 \mathrm{AC} \times \mathrm{FL}+0.0316 \mathrm{BPD}+0.0457$ $\mathrm{AC}+0.1623 \mathrm{FL}$ In all cases, the sonographic fetal biometric measurements were performed within 7 days before delivery to eliminate possible impact of duration between ultrasound examination and delivery on the accuracy of the measurements.

All neonates were weighted within 30 minutes of the delivery, and infant weight was recorded to the nearest gram.

Because the primary objective was to determine how maternal BMI affect the accuracy of sonographic, the EFW was compared with the actual birth weight $(A B W)$, and the difference between the EFW and the ABW (i.e. simple error) was recorded as the error in grams. The percentage error was defined as:

$\mathrm{EFW}-\mathrm{ABW} \times 100 / \mathrm{ABW}$.

The absolute error was defined as absolute value of EFW - ABW. The mean percentage error represented the sum of the positive (i.e. overestimation), and negative (i.e. underestimation) deviations from $A B W$.

\section{Statistical Analysis:}

Only data from patients with complete records were included in our analysis. The 
Hadlock 412, 13 formulas was used in all cases to calculate the EFW. The accuracy of fetal weight assessment was defined as the difference between the EFW determined on the most recent scan prior to delivery (always conducted no longer than 2 weeks before delivery) and the actual birth weight. To account for potential growth during the 2 week time interval between the last US assessment and delivery, the EFW was modeled by using a nonlinear random effects model (fetuses having separate growth paths), and the EFW was extrapolated to the GA at birth.

The best- fitting model using combinations of linear, quadratic, cubic, and logarithmic terms for GA was determined by using informationtheoretic methods (ie, the adjusted

\begin{abstract}
Akaike- information criterion). Accuracy was assessed by using the root- mean- squared error (RMSE) for the difference between birth weight and the predicted EFW. For comparisons between the BMI categories, the RMSE was normalized as a coefficient of variation.

Labor and delivery outcomes by BMI categories were analyzed by using $\chi^{2}$ testing for association. Adverse perinatal outcomes were also analyzed by using logistic regression with inclusion of the fetal GA at delivery as a covariate. A p value $<0.05$ was considered statistically significant. SAS version 9.12 software (SAS Institute, Inc., Cary, NC) was used for data management, screening for anomalies, descriptive statistics, and mixed model analyses.
\end{abstract}

\section{RESULTS}

As regard demographic data of the studied cases, the mean age was $(25.03 \pm$ 4.38) years, the mean GA was( $38.81 \pm$ 1.47 ) weeks, most of cases in PG about $(38 \%)$, the mean body mass index (BMI) was $(31.87 \pm 7.01) \mathrm{kg} / \mathrm{m}^{2}$, the mean us EFW was $(3716.26 \pm 362.61) \mathrm{g}$, the mean birth weight was $(3744.79 \pm 344.72) \mathrm{g}$ and mode of delivery was (44.7\%) in C.S and $(55.3 \%$ )in NVD (Table1). 
Table (1): Characteristics distribution of the study group

\begin{tabular}{|l|c|}
\hline Parameters & Analysis [N=150] \\
\hline Age (years) & $18-36[25.03 \pm 4.38]$ \\
\hline G.A (wks) & $37-42[38.81 \pm 1.47]$ \\
\hline Parity & \\
\hline PG & $16(10.7 \%)$ \\
\hline P1 & $57(38 \%)$ \\
\hline P2 & $39(26 \%)$ \\
\hline P3 & $27(18 \%)$ \\
\hline P4 & $8(5.33 \%)$ \\
\hline P5 & $3(2 \%)$ \\
\hline BMI [wt/(ht)^2] & $30(20 \%)$ \\
\hline Normal & $30(20 \%)$ \\
\hline Overweight & $30(20 \%)$ \\
\hline Obesity class I & $30(20 \%)$ \\
\hline Obesity class II & $30(20 \%)$ \\
\hline Obesity class III & $18.6-42.3[31.87 \pm 7.01]$ \\
\hline BMI [wt/(ht)^2] & $2750-4690[3716.26 \pm 362.61]$ \\
\hline Us EFW by $(\mathbf{g})$ & $2830-4600[3744.79 \pm 344.72]$ \\
\hline Birth Weight by (g) & \\
\hline Mode of delivery & $67(44.7 \%)$ \\
\hline CS & $83(55.3 \%)$ \\
\hline NVD & \\
\hline & \\
\hline
\end{tabular}

No statistically significant difference between body mass index according to demographic and clinical characteristics (Table 2).

Table (2): Comparison between body mass index according to US EFW by (gm) and birth weight

\begin{tabular}{|c|c|c|c|c|c|c|}
\hline Parameters & $\begin{array}{c}\text { Normal } \\
\text { (30) }\end{array}$ & $\begin{array}{c}\text { Overweight } \\
\text { (30) }\end{array}$ & $\begin{array}{c}\text { Obesity } \\
\text { class I } \\
(30) \\
\end{array}$ & $\begin{array}{c}\text { Obesity } \\
\text { class II } \\
(30)\end{array}$ & $\begin{array}{c}\text { Obesity } \\
\text { class III } \\
(30) \\
\end{array}$ & $\begin{array}{c}\text { p- } \\
\text { value }\end{array}$ \\
\hline \multicolumn{7}{|l|}{ Age (years) } \\
\hline Mean \pm SD & $23.57 \pm 4.16$ & $24.33 \pm 4.06$ & $25.77 \pm 5.06$ & $25.53 \pm 3.30$ & $25.93 \pm 4.91$ & \multirow{2}{*}{$>0.05$} \\
\hline Range & $18-35$ & $19-34$ & $18-36$ & $20-33$ & $18-36$ & \\
\hline \multicolumn{7}{|l|}{ G.A (wks) } \\
\hline Mean \pm SD & $39.17 \pm 1.64$ & $38.63 \pm 1.38$ & $38.80 \pm 1.47$ & $38.63 \pm 1.40$ & $38.83 \pm 1.46$ & \multirow{2}{*}{$>0.05$} \\
\hline Range & $37-42$ & $37-42$ & $37-42$ & $37-42$ & $37-42$ & \\
\hline \multicolumn{7}{|l|}{ Parity } \\
\hline $\mathrm{PG}$ & $4(13.3 \%)$ & $6(20.0 \%)$ & $3(10.0 \%)$ & $3(10.0 \%)$ & $1(3.3 \%)$ & \multirow{2}{*}{$>0.05$} \\
\hline Multipara & $26(86.7 \%)$ & $24(80.0 \%)$ & $27(90.0 \%)$ & $27(90.0 \%)$ & $29(96.7 \%)$ & \\
\hline
\end{tabular}

Also we found highly statistically significant difference between body mass index and US EFW (g) and birth weight (g) (Table 3). 
Table (3): Labor and Delivery Outcomes by BMI Category

\begin{tabular}{|c|c|c|c|c|c|c|}
\hline Proups & $\begin{array}{c}\text { Normal } \\
\text { (30) }\end{array}$ & $\begin{array}{c}\text { Overweight } \\
(\mathbf{3 0})\end{array}$ & $\begin{array}{c}\text { Obesity } \\
\text { class I } \\
(30)\end{array}$ & $\begin{array}{c}\text { Obesity } \\
\text { class II } \\
(30)\end{array}$ & $\begin{array}{c}\text { Obesity } \\
\text { class III } \\
(30)\end{array}$ & p-value \\
\hline \multicolumn{7}{|l|}{ UsEFW (g) } \\
\hline Mean \pm SD & $3448.17 \pm 416.91$ & $3542.37 \pm 271.43$ & $3711.47 \pm 295.12$ & $3863.73 \pm 218.36$ & $4015.57 \pm 269.15$ & \multirow{2}{*}{$<0.001$} \\
\hline Range & $2750-4300$ & $2980-4050$ & $2890-4120$ & $3410-4349$ & $3410-4690$ & \\
\hline \multicolumn{7}{|c|}{ Birth Weight (g) } \\
\hline Mean \pm SD & $3478.67 \pm 387.66$ & $3576.50 \pm 232.92$ & $3747.27 \pm 288.97$ & $3920.40 \pm 219.07$ & $4131.10 \pm 255.38$ & \multirow{2}{*}{$<0.001$} \\
\hline Range & $2830-4220$ & $3040-3980$ & $2890-4090$ & $3457-4400$ & $3470-4600$ & \\
\hline
\end{tabular}

The rate of CS increased significally with the increase of BMI 30\% in normal weight while $60 \%$ in class III obesity (Table 4).

Table (4): Comparison between body mass index according to mode of delivery

\begin{tabular}{|c|c|c|c|c|c|c|}
\hline $\begin{array}{l}\text { Groups } \\
\text { Mode of } \\
\text { delivery }\end{array}$ & $\begin{array}{c}\text { Normal } \\
\text { (30) }\end{array}$ & $\begin{array}{c}\text { Overweight } \\
\text { (30) }\end{array}$ & $\begin{array}{c}\text { Obesity class } \\
\text { I } \\
\mathbf{( 3 0 )}\end{array}$ & $\begin{array}{c}\text { Obesity class } \\
\text { II } \\
\mathbf{( 3 0 )}\end{array}$ & $\begin{array}{c}\text { Obesity } \\
\text { class III } \\
(30)\end{array}$ & p-value \\
\hline $\mathrm{CS}$ & $9(30.0 \%)$ & $10(33.3 \%)$ & $13(43.3 \%)$ & $17(56.7 \%)$ & $18(60.0 \%)$ & \multirow{3}{*}{$>0.05$} \\
\hline NVD & $21(70.0 \%)$ & $20(66.7 \%)$ & $17(56.7 \%)$ & $13(43.3 \%)$ & $12(40.0 \%)$ & \\
\hline Total & $30(100.0 \%)$ & $30(100.0 \%)$ & $30(100.0 \%)$ & $30(100.0 \%)$ & $30(100.0 \%)$ & \\
\hline
\end{tabular}

Statistically significant difference between US EFW by (g) and birth weight

by (g) versus body mass index in obesity class II and III (Table 5).

Table (5): US EFW by (g) and birth weight by (g) versus body mass index

\begin{tabular}{|l|c|c|c|}
\hline \multicolumn{1}{|c|}{ Parameters } & Us EFW (g) & Birth Weight (g) & \multirow{2}{*}{ p-value } \\
\cline { 1 - 3 } BMI Category & & $3478.67 \pm 387.66$ & \multirow{2}{*}{$>0.05$} \\
Normal & $3448.17 \pm 416.91$ & $3576.50 \pm 232.92$ & \\
\cline { 1 - 3 } Overweight & $3542.37 \pm 271.43$ & $3747.27 \pm 288.97$ & \\
\cline { 1 - 3 } Obesity class I & $3711.47 \pm 295.12$ & $3920.40 \pm 219.07$ & \\
\hline Obesity class II & $3863.73 \pm 218.36$ & $4131.10 \pm 255.38$ & \\
\hline Obesity class III & $4015.57 \pm 269.15$ & \\
\hline
\end{tabular}

\section{DISCUSSION}

Although considerable technical advances in ultrasound technology, such as tissue harmonics and multi-Hertz transducer technology, have been made during the past two decades, ultrasound imaging of obese patients remains challenging due to the adverse effects of adipose tissue on the propagation of soundwaves (Hendler et al., 2016).
Aksoy et al. (2015) investigated the possible effect of maternal obesity on the accuracy of sonographically predicted EFW during the third trimester shortly before the induction of labor. This was a prospective study of singleton pregnancies with sonographic fetal weight estimation prior to scheduled delivery. Women were classified according to current body mass index (BMI) into five categories: normal (BMI 18.5-24.9 kg/m ${ }^{2}, \quad \mathrm{n}=41$ ), overweight (BMI 25.0-29.9 $\mathrm{kg} / \mathrm{m}^{2}, \mathrm{n}=$ 
44), obese class I (BMI $30.0-34.9 \mathrm{~kg} / \mathrm{m}^{2}$, $\mathrm{n}=40$ ), obese class II (BMI, 35.0-39.9 $\left.\mathrm{kg} / \mathrm{m}^{2}, \mathrm{n}=38\right)$ and obese class III (BMI $\geq$ $40.0 \mathrm{~kg} / \mathrm{m} 2, \mathrm{n}=35)$. They observed no statistically significant differences among the five study groups in terms of mean gravidity, parity and gestational age.

This study has demonstrated no statistically significant difference between body mass index according to demographic and clinical characteristics.

In the study done by Aksoy et al. (2015), the demographic and clinical characteristics did not differ between the study groups, except for maternal age, which was $25.19 \pm 5.39$ years, $26.56 \pm$ 6.31 years, $25.30 \pm 5.52$ years, $30.42 \pm$ 5.18 years and $30.20 \pm 5.88$ years in the normal weight, overweight, class I, class II and class III groups, respectively.

In our study, there was a highly statistically significant difference between body mass index and US EFW by (gm) and birth weight by (gm).

Aksoy et al. (2015) observed no significant differences between the groups with respect to EFW and ABW. When intra-group comparisons between EFW and $\mathrm{ABW}$ were made, significant differences were found in the obese classes II and III groups. Significant differences in the mean absolute error and the mean absolute percentage error were found between all five groups. A significant difference in the magnitude of the mean absolute error and the absolute percentage error was observed with increasing maternal obesity.

In our study, a significant positive correlation between body mass index classification according to delivery by CS.
Also, there was a statistically significant difference between US EFW by (gm) and birth weight by (gm) versus body mass index in obesity class II and III.

Wolfe et al. (2016) analyzed data from 1622 examinations that were performed at a mean gestational age of 28.5 weeks to determine whether maternal obesity affected visualization of fetal anatomy. They reported a greater risk of suboptimal visualization when BMI $\left(\mathrm{kg} / \mathrm{m}^{2}\right)$ was above the 90th percentile.

Another study conducted by Dashe et al. (2019) showed that increasing maternal BMI limits the visualization of the fetal anatomic structures during a standard second-trimester ultrasound examination. Thornburg (2016) analyzed 112 women who underwent standard ultrasound examination over a 5-year period.

Dammer et al. (2016) have investigated the factors that affect sonographic EFW prediction evaluating the effect of nine different factors, including maternal $\mathrm{BMI}$; presentation of the fetus; time interval between estimation and delivery; fetal gender; fetal weight; placenta location; amniotic fluid index; gestational age and degree of operator experience, on the accuracy of EFW measurements. That retrospective study, which was conducted on 820 singleton pregnancies with gestational age ranging from 22 to 42 weeks, reported that of the nine evaluated factors that may affect accuracy of EFW measurements, only time interval $>7$ days between estimation and delivery had an adverse effect on prediction.

Caughey (2018) summarized the impact the EFW can have on the mode of delivery. A study by Little et al found that 
patients who underwent a recent sonographic examination were $50 \%$ more likely to undergo a cesarean delivery, with an even greater impact if the EFW was greater than $3500 \mathrm{~g}$. This finding lends credence to the conclusion that clinicians rely on the EFW in their management of labor and decision making regarding the mode of delivery.

Kritzer et al. (2016) quantitated the impact, if any; an increasing maternal BMI has on the accuracy of sonographic EFW obtained within 2 weeks of delivery. Estimation of the EFW near delivery does not appear to be similarly affected by the maternal body habitus. Sonography performed in a dedicated obstetric ultrasound unit within 2 weeks of delivery had a relatively low percentage error for estimation of fetal weight, and this error rate did not vary substantially by maternal BMI classification.

Aksoy et al. (2015) found significantly higher mean absolute error and mean absolute percentage error in the higher BMI category. Strong positive correlations were observed between BMI and the mean absolute error or the mean absolute percentage error; these correlations were statistically significant. Therefore, maternal obesity decreases the accuracy of sonographic fetal weight estimation, in our study there was a statistically significant difference between US EFW by (gm) and birth weight by (gm) versus body mass index in obesity class II and III.

\section{CONCLUSION and RECOMMENDATION}

It is concluded from this study that obesity brings many health hazards on obese mothers and their babies as obese mothers exposed to cesarean section delivery, adverse pregnancy outcome on their babies as preterm baby, macrisomic baby and congenital anomalies.

Obesity shows strong associations with antenatal complications including increased incidence of pre-eclampsia, gestational hypertension, gestational diabetes and delivery complications including, premature rupture of membrane, preterm delivery, macrosomia, shoulder dystocia, induction of labor, cesarean delivery and postnatal complications including postpartum hemorhage and postoperative urinary tract infection while underweight women appear to have better pregnancy outcomes than even women with BMI within the normal range.

Even moderate overweight has a significant deleterious effect on the outcome of pregnancy, and obesity leads to major maternal and fetal complications.

Our study has shown that increasing maternal obesity decreases the accuracy of sonographic EFW measurement. Clinicians should be aware of the limitations of sonographic EFW prediction, especially in obese patients.

\section{REFERENCES}

1. Aksoy, H., Aksoy, Ü., Karadağ, Ö. İ., Yücel, B., Aydın, T. and Babayiğit, M. A. (2015): Influence of maternal body mass index on sonographic fetal weight estimation prior to scheduled delivery. Journal of Obstetrics and Gynaecology Research, 41(10): 1556-1561.

2. American College of Obstetricians and Gynecologists (ACOG) (2013): Practice Bulletin No.137: gestational diabetes mellitus. Obstet. Gynecol., 122(2 Pt 1): 406416. 
3. Caughey AB (2018): Obstetrical ultrasound for the estimated fetal weight: is the information more harm than benefit? Am J Obstet Gynecol; 207:239-240.

4. Dammer, U., Goecke, T. W., Voigt, F., Schmid, M., Mayr, A., Schild, R. L., ... \& Faschingbauer, F. (2016): Sonographic weight estimation in fetuses with breech presentation. Arch Gynecol Obstet; 287: 851-858.

5. Dashe, J. S., McIntire, D. D., and Twickler, D. M. (2019): Maternal obesity limits the ultrasound evaluation of fetal anatomy. Journal of ultrasound in Medicine, 28(8): 1025-1030.

6. Dudley NJ. (2015): A systematic reviewof the ultrasound estimation of fetal weight. Ultrasound Obstet Gynecol., 25: 80-89.

7. Fuchs, F., Houllier, M., Voulgaropoulos, A., Levaillant, J. M., Colmant, C., Bouyer, J., and Senat, M. V. (2018): Factors affecting feasibility and quality of secondtrimester ultrasound scans in obese pregnant women. Ultrasound Obstet Gynecol; 41: 4046.

8. Hendler, I., Blackwell, S. C., Bujold, E., Treadwell, M. C., Wolfe, H. M., Sokol, R. J, and Sorokin, Y. (2016): The impact of maternal obesity on midtrimester sonographic visualization of fetal cardiac and craniospinal structures. International journal of obesity, 28(12), 1607-1611.

9. Hendler, I., Blackwell, S. C., Bujold, E., Treadwell, M. C., Mittal, P., Sokol, R. J. and Sorokin, Y. (2019): Suboptimal SecondTrimester Ultrasonographic Visualization of the Fetal Heart in Obese Women Should We
Repeat the Examination? Journal of Ultrasound in Medicine, 24(9): 1205-1209.

10. Horton A, Diaz $\mathbf{J}$ and Mastrogiannis $\mathbf{D}$ (2018): Accuracy of estimated fetal weight by ultrasonography compared with the Leopold maneuver and effect of maternal obesity. Obstet Gynecol., 123 (Suppl): 193S193S.

11. Goetzinger, K. R., Tuuli, M. G., Odibo, A. O., Roehl, K. A., Macones, G. A., and Cahill, A. G (2018): Screening for fetal growth disorders by clinical exam in the era of obesity. J Perinatol; 33:352-357.

12. Kritzer $S$, Magner $K$ and Warshak $C R$ (2018): Increasing maternal body mass index and the accuracy of sonographic estimation of fetal weight near delivery. J Ultrasound Med; 33: 22173-2179.

13. Racusin, D., Stevens, B., Campbell, G. and Aagaard, K. M. (2018): Obesity and the risk and detection of fetal malformations. In Seminars in Perinatology, 36(3):213-221.

14. Thornburg LL. (2018): Re: Factors affecting feasibility and quality of secondtrimester ultrasound scans in obese pregnant women. Ultrasound Obstet Gynecol., 41: 742.

15. Thornburg, L. L., Miles, K., Ho, M. and Pressman, E. K. (2019): Fetal anatomic evaluation in the overweight and obese gravida. Ultrasound in Obstetrics \& Gynecology, 33(6), 670-675.

16. Wolfe, H. M., Sokol, R. J., Martier, S. M., and Zador, I. E. (2016): Maternal obesity: A potential source of error in sonographic prenatal diagnosis. Obstet Gynecol., 76: 339342. 


\section{تأثير سمنة الأم على دقة تحديا وزن الجنين باستخدام الموجات فوق الصوتية}

أحمد الغتدور، عاصم أنور، السيد الدسوقى

خلفية البحث: تعتبر السمنه من المشاكل المعاصره لتحديد وزن الجنين بدقه.

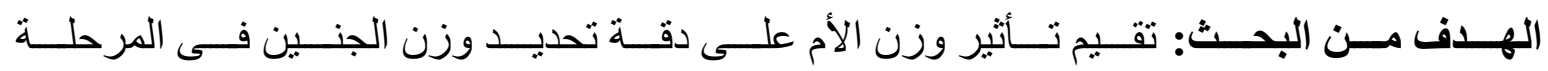
الثالثة من الحمل قبل الو لادة بسبعة أيام.

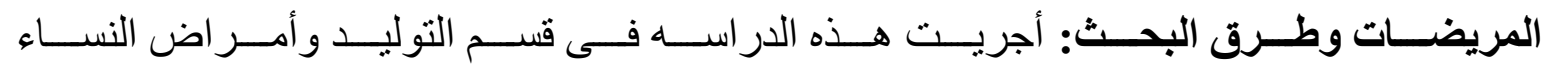

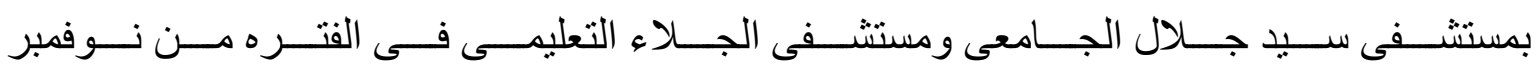

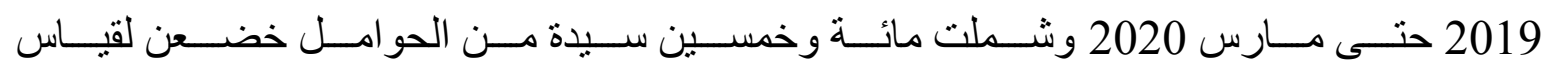

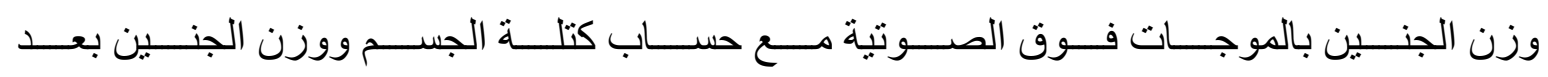
الو لادة.

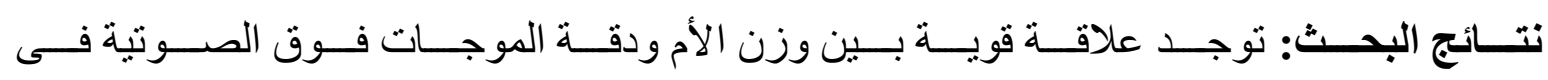
تحديد وزن الجنين.

الأستتتاج: يعتبر زيادة وزن الأم عائقاً أمام تحديد وزن الجنين بدقة. 